\title{
Effects of Ultra-Sonication and Agitation on Bioactive Compounds and Structure of Amaranth Extract
}

\author{
Maruf Ahmed ${ }^{1, \dagger}$, Karna Ramachandraiah ${ }^{2, \dagger}$, Gui-Hun Jiang ${ }^{3}$ and Jong Bang Eun ${ }^{4, *}$ \\ 1 Department of Food Processing and Preservation, Hajee Mohammad Danesh Science and Technology \\ University, Dinajpur 5400, Bangladesh; maruf@hstu.ac.bd \\ Department of Food Science and Biotechnology, Sejong University, Seoul 05006, Korea; karna@sejong.ac.kr \\ 3 School of Public Health, Jilin Medical University, Jilin, Changchun 130026, China; jiangguihun1@naver.com \\ 4 Department of Food Science and Technology and BK 21 PlusProgram, Graduate School of Chonnam \\ National University, Gwanju 61186, Korea \\ * Correspondence: jbeun@jnu.ac.kr; Tel.: +82-62-530-2145; Fax: +82-62-530-2149 \\ + Both authors contributed equally to this manuscript.
}

Received: 17 July 2020; Accepted: 11 August 2020; Published: 13 August 2020

\begin{abstract}
Amaranth is an excellent source of various bioactive compounds that could be beneficial in the prevention of some human diseases. This study investigated the extraction and characterization of bioactive compounds from amaranth using ultra-sonication and agitation at 30,50 and $70{ }^{\circ} \mathrm{C}$. Color $\mathrm{L}^{*}$ values showed significant $(p<0.05)$ differences at $70{ }^{\circ} \mathrm{C}$ between ultra-sonication and agitation. Ultra-sonication temperature had significant effect on $\mathrm{L}^{*}$ and $\mathrm{a}^{*}$ values whereas agitation temperature did not have a significant effect on $\mathrm{L}^{*}, \mathrm{a}^{*}$ and $\mathrm{b}^{*}$ values. No significant $(p<0.05)$ differences were found in terms of total phenol, total flavonoid, $\mathrm{DPPH}^{\bullet+}, \mathrm{ABTS}^{+}$scavenging activity, betacyanins, betaxanthin and betanicaicd between ultra-sonication and agitation. However, temperature had a significant $(p<0.05)$ effect on total phenol $(8.64-10.598 \mathrm{mg} / \mathrm{g}), \mathrm{DPPH}^{+}$scavenging activity (84.36-94.44\%), betacyanins (4585.95-5325.32 mg/100 g), betaxanthin (1312.56-1524.06 mg/100 g) and betalamic acid (1408.15-1790.22 mg/100 g) in ultra-sonication. Higher temperature $\left(70^{\circ} \mathrm{C}\right)$ showed greater amount of arbutin and hydroxybenzoic acid than those of lower temperature $\left(30^{\circ} \mathrm{C}\right)$ for both extraction methods. Meanwhile, temperature did not affect vanillic acid, $p$-coumaric acid and ferulic acid for both samples. Fourier-transformed infrared (FTIR) spectrometry showed that ultra-sonication and agitation resulted in similar effect on the structure of amaranth extracts. Higher temperature was correlated with bioactive compounds, which were observed by principal component analysis (PCA). Therefore, agitation at $70^{\circ} \mathrm{C}$ could be used as an alternative for ultra-sonication to improve the bioactive compounds and antioxidant activities of amaranth. In addition, agitation and ultra-sonication techniques might be served as an alternative of conventional technique.
\end{abstract}

Keywords: Amaranth; ultra-sonication; agitation; Fourier-transformed infrared; Antioxidants properties

\section{Introduction}

Amaranthus (family Amaranthaceae) is a major source of vitamins, such as folic acid, protein, dietary fiber, and minerals [1]. This underutilized plant is also known to contain valuable bioactive compounds that include betacyanins, betaxanthins, and polyphenols, which can inhibit deteriorative diseases that include cardiovascular disorders and inflammatory responses [2]. In particular, amaranthus leaves contain several types of betalains such as amaranthin, isoamranthin, methyl derivative of arginine betaxanthin and betamic acid [2]. Furthermore, different types of phenolic compounds such as gallic acid, chlorogenic acid, ferulic acid, salicylic acid, rutin and quercetin have also been studied in 
many Amaranthus species [3]. A few Amaranthus species have also shown strong antioxidant and anti-proliferative activity on Ehrlich's ascites carcinoma cells [4]. Amaranth bioactive compounds have been used as abundant sources of natural bioactive compounds and natural food colorant [5]. Natural pigments have been widely used as natural preservatives in cosmetic products, drugs and food [6]. Various potential applications such as composite cookies, gluten-free bread and juice can be produced using amaranth leaves and seeds [7].

Antioxidants derived from natural sources such as fruits and vegetables have been gaining popularity due to various health benefits. However, the perishable nature and lower shelf-life necessitate fruits and vegetables to be processed. The traditional methods of processing involve extraction of bioactive compounds using solvents such as water, methanol and ethanol [8-10]. Recently, ultrasound-assisted and agitation extractions are considered to be more efficient for the derivation of valuable bioactive compounds from different sources. Particularly, ultrasound has been shown to promote the release of flavonoid compounds in raspberry and blueberry puree due to the disruption of the cell wall [11]. Since the amount of cavitation bubbles is contingent upon temperature, it is likely that increased ultrasonic temperature may improve cavitation and thereby cause cell rupture. Nonetheless, ultrasound frequency and power could have a negative impact on flavonoid content due to oxidation [12]. It has been reported that, apart from ultrasonic extraction temperature, time also influences the extraction of flavonoid from pumpkin [13]. Longer ultrasonic extraction time was reported to decrease the flavonoid content in vegetables [14]. Ultrasound extraction techniques used as rapid and green extraction process have been utilized for the derivation of bioactive compounds from natural sources [15]. Agitation was also shown to improve the extraction of phenolic compounds from olive leaves due to the rupture of the cell and the subsequent release of phenolic compounds from the cell matrix [16].

Color is an important parameter that influences the acceptance of foods and beverages. In the food industry, synthetic colorants are widely used to impart desired colors to food products. However, studies have shown that many synthetic food colorants likely to be carcinogenic to consumers [17]. Therefore, processors are utilizing natural colorants as a viable alternative. In this regard, betalains from red amaranth could be an alternative source of natural colorant and antioxidant compounds. Owing to such benefits, this polyphenol has received great attention by food manufacturers in recent times [8]. However, the investigations on the extraction of antioxidant from red amaranthus leaves using ultra-sonication and agitation are limited. Therefore, the objective of this study was to investigate the effects of ultra-sonication and agitation on phenolic compounds from red amaranth. In addition, chemical bonds in the extract samples were identified by using Fourier-transform infrared (FTIR). Furthermore, principal component analysis (PCA) was used to establish the correlation between nutritional components and extraction techniques.

\section{Materials and Methods}

\subsection{Sample Collection and Preparation}

Fresh red amaranth (Amaranthuscruentus) was procured from the local market, Dinajpur, Bangladesh. The plant materials were washed in running tap water to eliminate any dirt, and other surface impurities. Using a stainless-steel knife, the collected samples (approximately 500 to $800 \mathrm{~g}$ ) were then cut into small pieces and the leafy parts were separated from the roots. The freshly cut small pieces (leafy parts) were placed in a dryer at $40{ }^{\circ} \mathrm{C}$ for $25 \mathrm{~h}$. The dried red amaranth samples were pulverized using a blender and stored at $4{ }^{\circ} \mathrm{C}$ until further analysis.

\subsection{Chemical and Reagents}

2,2-azino-bis (3-ethylbenzthiazoline-6-sulfonic acid) $\left(\mathrm{ABTS}^{+}\right)$, 1,1-diphenyl-2-picrylhydrazyl $\left(\mathrm{DPPH}^{+}\right)$, rbutin, Ferulic acid, $p$-coumaric acid, Hydroxybenzoic acid, Vanillic acid, and Folin-Ciocalteu reagent, were obtained from Sigma-Aldrich, Chemical Co. (St. Louis, MO, USA). Other chemicals, 
namely, sodium carbonate, sodium chloride, aluminum chloride, sodium nitrite, and lead acetate, used in the present study were of analytical grade.

\subsection{Extraction of Amaranth Powder}

Ultra-Sonication and Agitation Extraction

In particular, $6.25 \mathrm{~g}$ of amaranth powder was taken in a $250-\mathrm{mL}$ conical flask and mixed with $100 \mathrm{~mL}$ of distilled water and placed in an ultra-sonicator bath (Bandelin Sonorex, RK510H, $35 \mathrm{kHz}$, Germany) and agitated using a shaking water bath (JSSB-50T, South Korea) at $100 \mathrm{rpm}$, respectively, at 30,50 and $70{ }^{\circ} \mathrm{C}$ for $5 \mathrm{~min}$. The extracted sample was filtered through a cheese cloth, and then vacuum filtered through a Whatman filter paper No.1. The quality parameters of the filtered extract were then analyzed.

\subsection{Hunter Color Values}

Das et al. [18] method was followed to determine the color of the amaranth extracts using a Chroma meter (Minolta, CR-300, Osaka, Japan). Readings were expressed as $\mathrm{L}^{*}, \mathrm{a}^{*}$ and $\mathrm{b}^{*}$ parameters.

\subsection{Determination of Amaranthus Pigments}

Amaranthus pigments were quantified using the modified method described by Kumar et al. [9]. In particular, a $1 \mathrm{~mL}$ aliquot was diluted with $9.0 \mathrm{~mL}$ of distilled water and absorbance was measured at 538, 480 and $430 \mathrm{~nm}$ for betacyanins, betaxanthins and betalamic acid, respectively, using a spectrophotometer (Optizen 2120 UV, Mecasys Co., South Korea). The pigment content was quantified based on the following equation.

$$
(\mathrm{mg} / 100 \mathrm{~g} \text { of dry matter })=(\mathrm{A} \times \mathrm{MW} \times \mathrm{V} \times \mathrm{DF} \times 100) /(\varepsilon \times \mathrm{L} \times \mathrm{W})
$$

where A = Absorbance; $\mathrm{MW}=$ Molecular weight of betacyanins; (726.6) betaxanthins (309) and betalamic acid (212); $\mathrm{V}=$ Solution volume; $\mathrm{DF}=$ Dilution factor; $\varepsilon=$ Molar extinction coefficient of betacyanins $\left(5.66 \times 10^{4} \mathrm{M}^{-1} \mathrm{~cm}^{-1}\right)$, betaxanthins $\left(48,000 \mathrm{M}^{-1} \mathrm{~cm}^{-1}\right)$, and betalamic acid $\left(24,000 \mathrm{M}^{-1} \mathrm{~cm}^{-1}\right)$, $\mathrm{W}=$ Sample weight $(\mathrm{g})$.

\subsection{Determination of Total Phenol Content}

The total phenol content of the amaranth sample was measured according to the method described by Lee et al. [19] with some modification. Amaranth extract $(1 \mathrm{~mL})$ was diluted 10 times with distilled water and $200 \mu \mathrm{L}$ samples along with $1.5 \mathrm{~mL}$ of $10 \%$ Folin-Ciocalteu reagent in test tubes for $5 \mathrm{~min}$. Following the $1.5-\mathrm{mL}$ addition of sodium carbonate (7.5\%), the samples were incubated for $30 \mathrm{~min}$ in the dark at room temperature. A 725-nm wavelength was used to measure the absorbance the solution using a UV/Vis spectrophotometer (Optizen 2120 UV, South Korea); Gallic acid was also prepared for the calibration and results were expressed as $\mathrm{mg}$ per gram sample $(\mathrm{mg} / \mathrm{g})$.

\subsection{Determination of the Flavonoid Content}

Hajimahmoodi et al. [20] method was followed for the determination of flavonoid content Briefly, $1 \mathrm{~mL}$ diluted sample ( 5 times) was treated with $4 \mathrm{~mL}$ distilled water along with $0.3 \mathrm{~mL}$ of $5 \%$ sodium nitrite in a test tube for $5 \mathrm{~min}$. Following incubation, each tube was treated with $0.3 \mathrm{~mL}$ of aluminum chloride and incubated for $6 \mathrm{~min}$ at room temperature. Then, $2 \mathrm{~mL}$ sodium hydroxide was mixed and absorbance was recorded at a 510-nm wavelength using a UV/Vis spectrophotometer. Rutin was used for the preparation of standard curve and results were expressed as mg per gram sample $(\mathrm{mg} / \mathrm{g})$. 


\subsection{Determination of Phenolic Compounds Using High-Performanceliquid Chromatography (HPLC)}

Phenolic compounds were determined according to the method described by Yim and Nam [21] using a Chromatography instrument (LC-20 Avp Shimadzu Co., Japan) along with a diode array detector. Separation of phenolic compounds was done by using A C18 HPLC column $(300 \times 3.9 \mathrm{~mm})$. The mobile phases were constituted by $2 \%(v / v)$ aqueous acetic acid (solvent $\mathrm{A}$ ) and $0.5 \%(v / v)$ acetic acid in 50\% acetonitrile (solvent B) with the following linear gradient: $2 \%$ B from 0 to $5 \mathrm{~min} ; 2 \%$ to $55 \%$ B from 5 to $55 \mathrm{~min} ; 100 \%$ B from 55 to $65 \mathrm{~min} ; 10 \%$ B from 65 to $70 \mathrm{~min}$; and post run with 2\% B for $6 \mathrm{~min}$. Then, $0.45-\mu \mathrm{m}$ filters were used to filter the samples and $20 \mu \mathrm{L}$ of samples, and standard solutions were injected into the HPLC system. The flow rate was $1 \mathrm{~mL} / \mathrm{min}$ at $30^{\circ} \mathrm{C}$. Chromatograms were recorded at $280 \mathrm{~nm}$ for arbutin, hydroxybenzoic acid and vanillic acid and at $320 \mathrm{~nm}$ for $p$-coumaric acid and ferulic acid. Five concentrations (20 to $100 \mathrm{ppm}$ ) were used to prepare the calibration curve and regression equations were found by plotting the area of the standard solutions against concentrations. The quantities of phenolic compounds were calculated by comparing the retention time of the samples with those of the standard solutions. Data were shown as mg per gram sample $(\mathrm{mg} / \mathrm{g})$.

\subsection{Antioxidant Capacity Using DPPH ${ }^{+}$Assay}

$\mathrm{DPPH}^{+}$assay was performed according to the method of Dong et al. [22] with some modifications. In particular, a stock solution was prepared with $24 \mathrm{mg}$ of $\mathrm{DPPH}^{+}$using methanol. The stock solution $(10 \mathrm{~mL})$ was then diluted with methanol to form the working solution. Water was used to dilute $\left(5\right.$ times) the Amaranth extract $(1 \mathrm{~mL})$ and samples $(200 \mu \mathrm{L})$ were mixed with the DPPH ${ }^{+}$ solution $(2 \mathrm{~mL})$. Following a 30-min incubation, the absorbance of the solution was recorded at 515 $\mathrm{nm}$ using a UV/Vis spectrophotometer. The following formula was used to calculate the $\mathrm{DPPH}^{+}$ radical-scavenging activity:

$$
\text { Scavenging activity }(\%)=\left(1-\mathrm{A}_{1} / \mathrm{A}_{0}\right) \times 100
$$

where $\mathrm{A}_{0}=$ absorbance of control solution and $\mathrm{A}_{1}=$ absorbance of sample solution. Sample absorbance was calculated without the absorbance of $\mathrm{DPPH}^{+}$solution.

\subsection{Antioxidant Capacity Using ABTS $^{+}$Assay}

The $\mathrm{ABTS}^{+}$assay was performed as described by Dong et al. [22] with minor modifications. Briefly, $7.4 \mathrm{mM} \mathrm{ABTS}{ }^{+}$solution potassium persulfate $(2.6 \mathrm{mM})$ was prepared in equal amounts and placed in the dark $(12 \mathrm{~h})$. Methanol was used to dilute the solution until an absorbance of $1.1 \pm 0.04$ at $734 \mathrm{~nm}$ was attained. Amaranth samples $(1 \mathrm{~mL}$, diluted 5 times in water) were incubated with $2 \mathrm{~mL}$ $\mathrm{ABTS}^{+}$solution for $10 \mathrm{~min}$ and the absorbance was recorded at $734 \mathrm{~nm}$. $\mathrm{ABTS}^{+}$scavenging value was calculated based on the following formula:

$$
\text { Scavenging activity }(\%)=\left(1-\mathrm{A}_{1} / \mathrm{A}_{0}\right) \times 100
$$

where $\mathrm{A}_{0}=$ absorbance of control solution (without sample) and $\mathrm{A}_{1}=$ absorbance of sample solution. Sample absorbance was quantified by subtracting the sample absorbance values that was incubated without $\mathrm{ABTS}^{+}$solution.

\subsection{Fourier-Transformed Infrared (FTIR) Spectrometry}

Chemical bonds of amaranth extracts were measured by Perkin Elmer FTIR spectrophotometer (Perkin Elmer, Inc., Waltham, MA, USA). Sample was kept on universal diamond ATR top-plate and then $120 \mathrm{~N}$ was applied on the top of the sample. A 380- to $4000-\mathrm{cm}^{-1}$ wavelength at a 4- $\mathrm{cm}^{-1}$ resolution with four scans was also used. Alcohol was used to clean the universal diamond ATR top-plate. 


\subsection{Statistical Analysis}

Phenolic compounds were measured twice whereas other parameters were carried out thrice. Statistical software (SPSS for Windows Version 21.0) was used to carry out the one-way analysis of variance (ANOVA) using the Duncan's test at 5\% significance level. Results expressed as mean vale \pm standard deviation (SD). Principal Component Analysis (PCA) was performed using XLSTAT 2017.

\section{Results and Discussion}

\subsection{Effects of Ultra-Sonication and Agitation on Color Values of Amaranthus Extracts}

$\mathrm{L}^{*}, \mathrm{a}^{*}$ and $\mathrm{b}^{*}$ values of amaranth extracts obtained by means of ultra-sonication and agitation temperatures were shown in Figure 1. Higher $L^{*}$ values were observed with ultra-sonication samples than with that of agitation samples. Significant $(p<0.05)$ differences in $L^{*}$ values were observed between ultra-sonication and agitation samples at higher temperatures. Ultra-sonication temperature had significant effect on $L^{*}$ and $a^{*}$ values whereas agitation temperature did not exhibit any significant effect on $L^{*}, a^{*}$ and $b^{*}$ values. On the other hand, $b^{*}$ values did not show any significant differences between ultra-sonication and agitation samples. The changes in color might be related to betacyanin content and various isomerized forms such as betaxanthin and betalamic acid. A good correlation was obtained between the $\mathrm{L}^{*}$ values and the amaranth pigments $(r$ values of $0.80,0.80$, and 0.88 for betacyanins, betaxanthin and betanic acid, respectively, at $p<0.05)$. However, no correlation was observed between $\mathrm{a}^{*}$ and $\mathrm{b}^{*}$ values and the amaranth pigments. While $\mathrm{L}^{*}$ and $\mathrm{a}^{*}$ values were much lower, $b^{*}$ values were found to be much higher than that of powders derived from different parts of the amaranthus species [3]. The deviation can be attributed to differences in cultivar and processing environments [3].

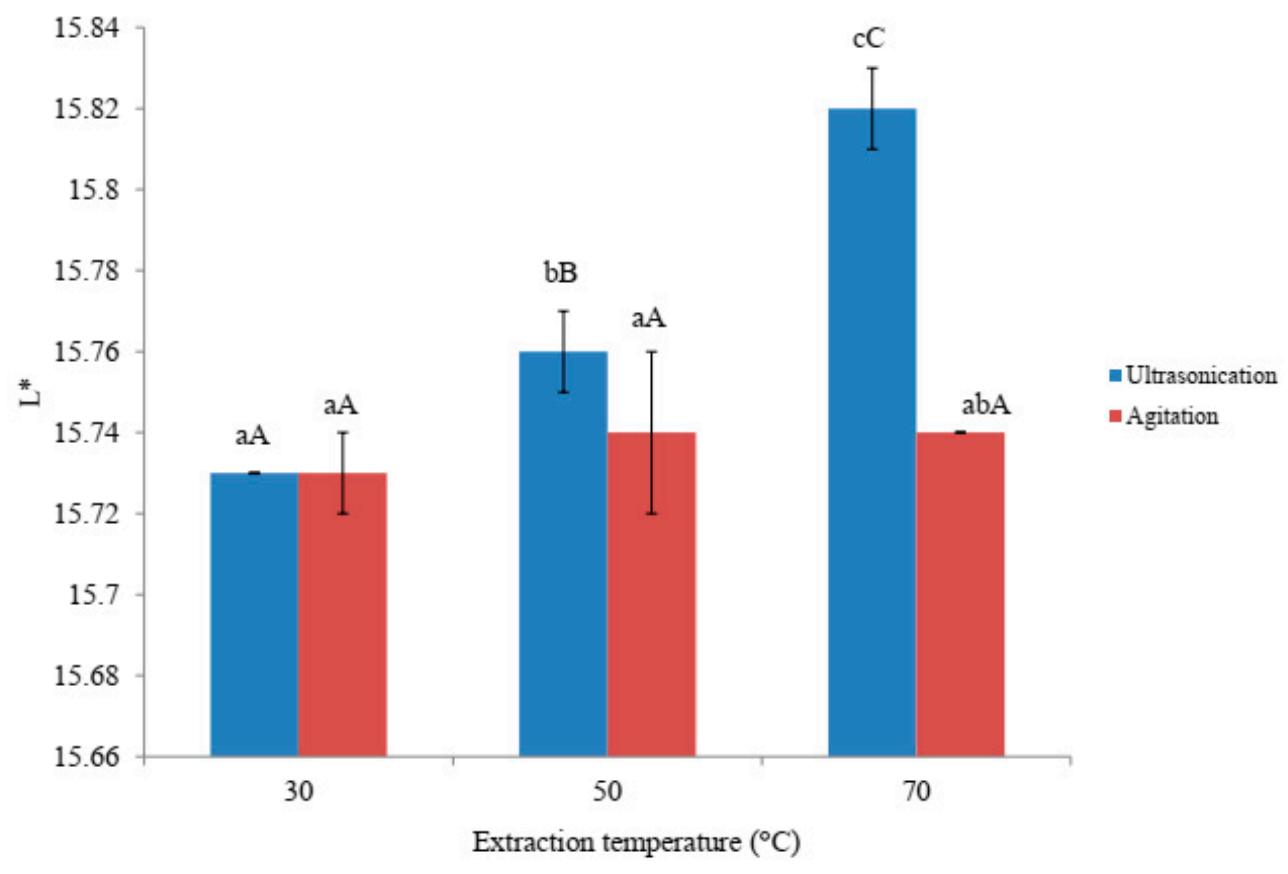

(A)

Figure 1. Cont. 
Extraction temperature $\left({ }^{\circ} \mathrm{C}\right)$

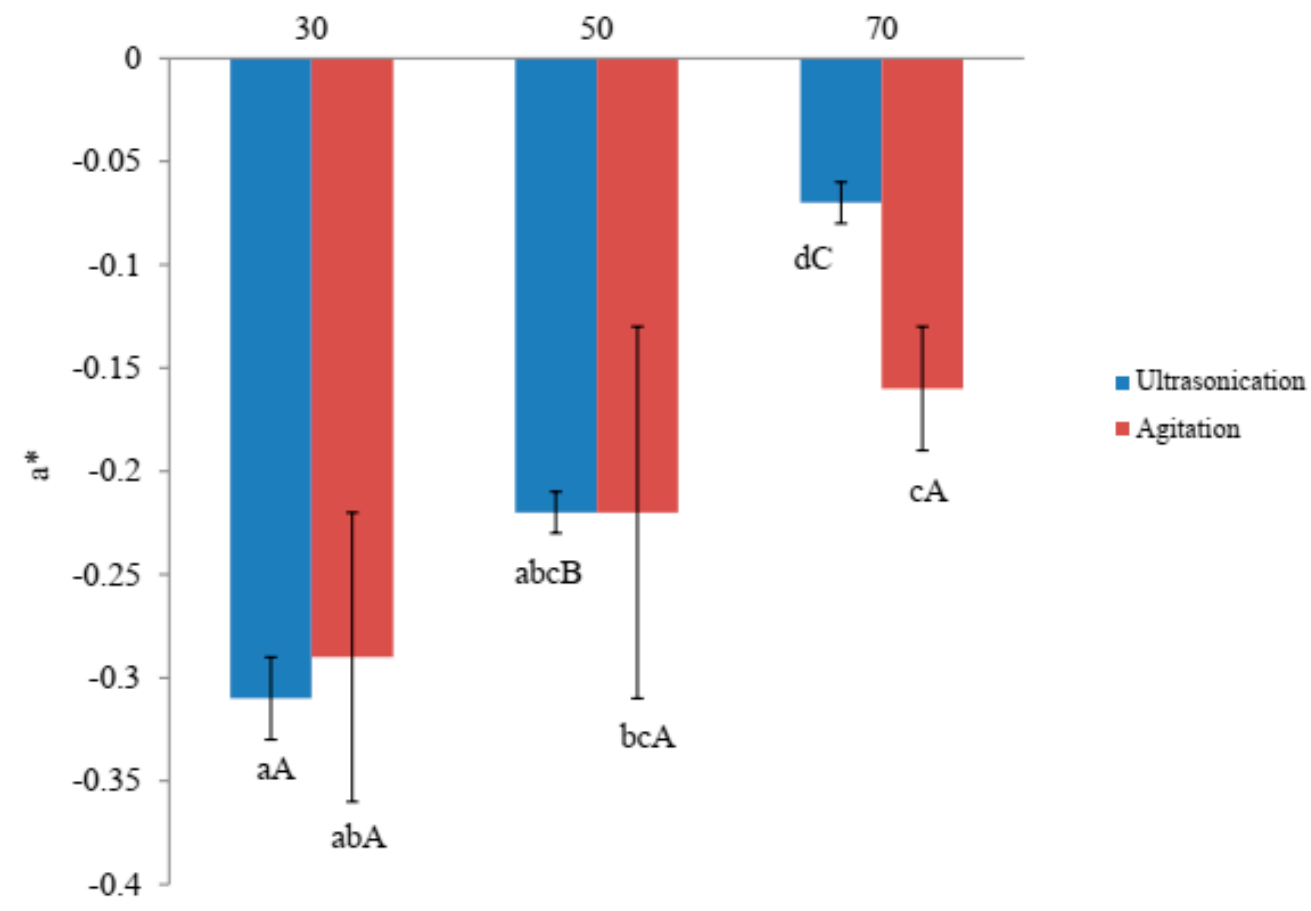

(B)

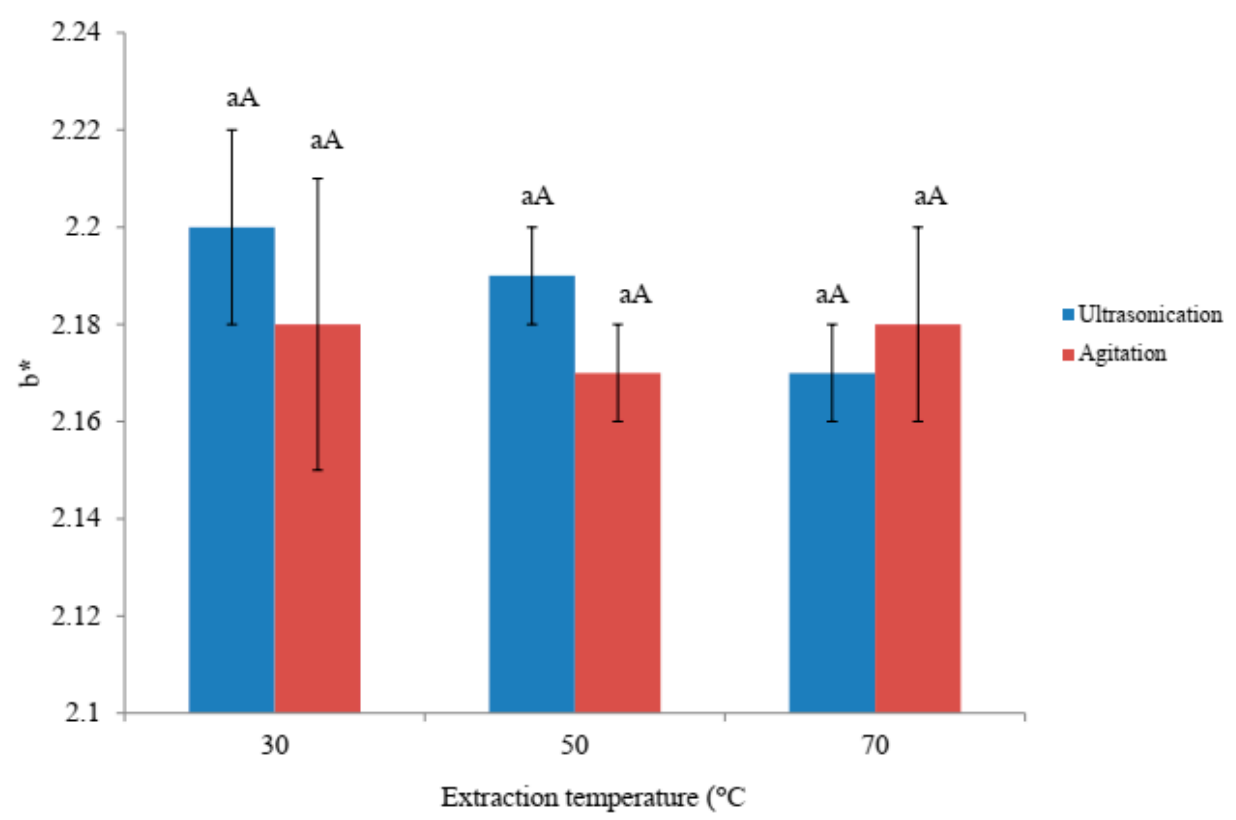

(C)

Figure 1. Effects of ultra-sonication and agitation on color values of amaranth extract. (A) $L^{*}$ values (B) $\mathrm{a}^{*}$ values $(\mathbf{C}) \mathrm{b}^{*}$ values. ${ }^{\mathrm{a}-\mathrm{d}}$ Means with same subscript alphabets are not significantly different $(p \leq 0.05)$ between each extraction method. A-C Means with same subscript alphabets are not significantly different $(p \leq 0.05)$ among different temperatures in each extraction method. 


\subsection{Effects of Ultra-Sonication and Agitation on Anti-Oxidative Properties}

The anti-oxidative properties of amaranthus extracts prepared using ultra-sonication and agitation were shown in Figures 2 and 3. Higher temperature $\left(70^{\circ} \mathrm{C}\right)$ resulted in increased $(p<0.05)$ total phenol and total flavonoid contents in ultra-sonication than with lower temperature $\left(30^{\circ} \mathrm{C}\right)$. On the other hand, agitation temperature did not significantly affect total phenol and total flavonoid contents. The highest total phenol $(10.598 \mathrm{mg} / \mathrm{g}$ for ultra-sonication and $95.40 \mathrm{mg} / \mathrm{g}$ for agitation) and total flavonoid contents $(5.559 \mathrm{mg} / \mathrm{g}$ for ultra-sonication and $5.324 \mathrm{mg} / \mathrm{g}$ for agitation) were obtained at $70^{\circ} \mathrm{C}$. The total phenol and total flavonoid content quantified in this study were comparable with the different parts of amaranthus species, as reported by Li et al. [3]. The higher phenol and flavonoid contents were observed at a higher temperature $\left(70^{\circ} \mathrm{C}\right)$ due to the release of bound polyphenols. It has been reported that bound polyphenols are released upon disruption of the cell wall [23]. It is likely that the cell wall could have been disrupted by higher temperature. The increased polyphenolic oxidase activity followed by sonication could have also affected the total phenol and total flavonoid content [24]. Total phenol and total flavonoid content could be enhanced by sonication in various juices $[25,26]$ and plants [27] have been reported. Ultra-sonication samples showed higher $\mathrm{DPPH}^{+}$and $\mathrm{ABTS}^{+}$scavenging activity than those of agitation samples (3A and $3 \mathrm{~B})$. For ultra-sonicated samples, the two radical scavenging activities increased with higher extraction temperature. Significant $(p<0.05)$ differences were found between lower and higher extraction temperature for ultra-sonication sample. On the other hand, different agitation temperatures did not influence the radical scavenging activities. The surge in $\mathrm{DPPH}^{+}$and $\mathrm{ABTS}^{+}$scavenging activity could be due to elevated levels of total phenol and total flavonoid contents. Higher correlation was observed between total phenol and ABTS ${ }^{+}(r$ value of 0.98 at $p<0.05)$ than between total phenol and $\mathrm{DPPH}^{+}(r$ value of 0.78 at $p<0.05)$. Similar correlations were found for total phenol and total flavonoid contents with the antioxidant capacity $[25,26]$. The same trend was not found for $\mathrm{DPPH}^{+}$and $\mathrm{ABTS}^{+}$for the techniques of ultra-sonication and agitation. That $\mathrm{DPPH}^{+}$showed higher values than $\mathrm{ABTS}^{+}$could be due to $\mathrm{DPPH}^{+}$acting as a stronger electron donor than $\mathrm{ABTS}^{+}$[28].

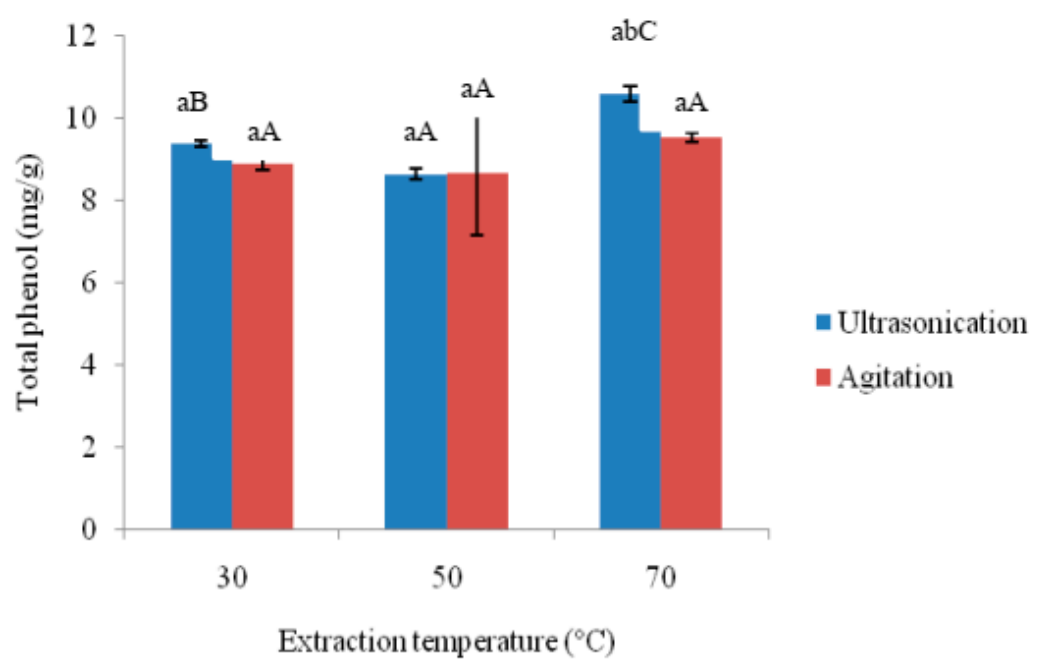

(A)

Figure 2. Cont. 


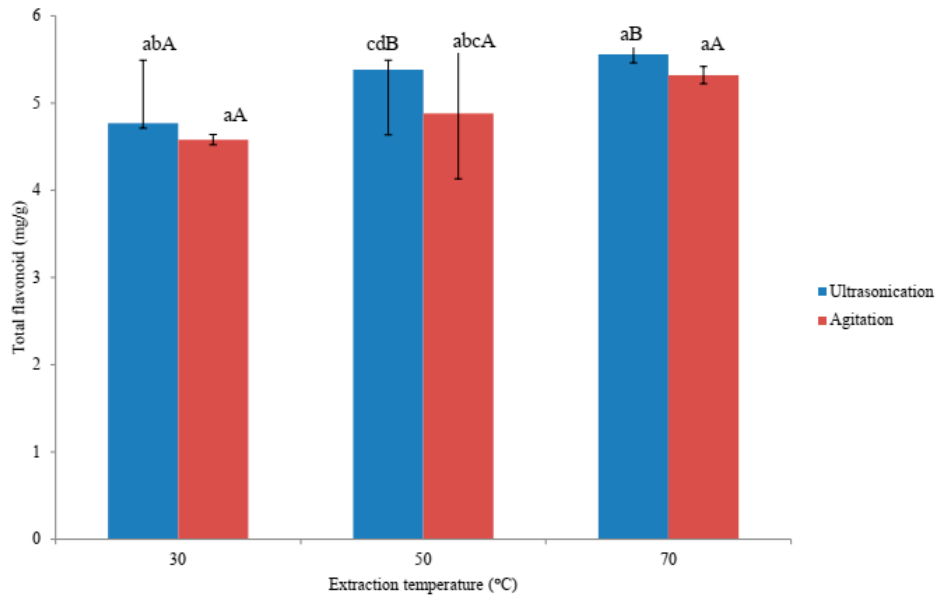

(B)

Figure 2. Effects of ultra-sonication and agitation on total phenol and total flavonoid content of amaranth extract. (A) Total phenol content (B) Total flavonoid content. ${ }^{\text {a-d }}$ Means with same subscript alphabets are not significantly different $(p \leq 0.05)$ between each extraction method. ${ }^{A-C}$ Means with same subscript alphabets are not significantly different $(p \leq 0.05)$ among different temperatures in each extraction method.

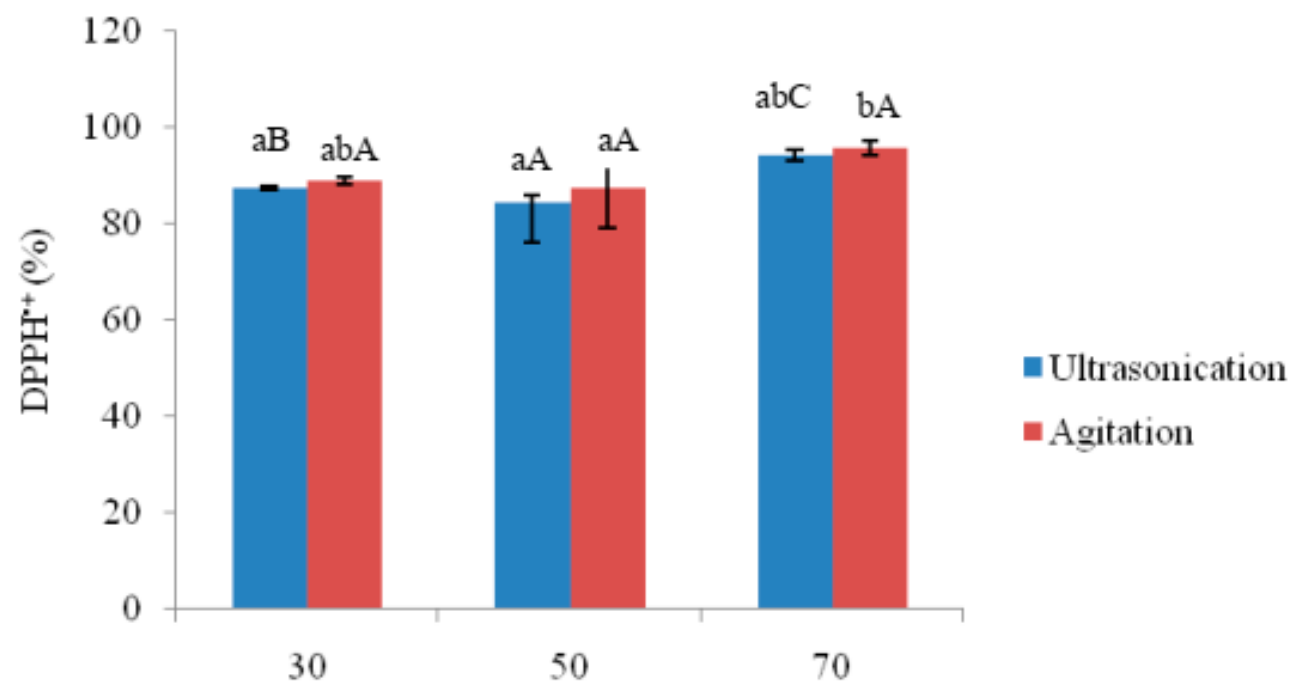

Extraction temperature $\left({ }^{\circ} \mathrm{C}\right)$

(A)

Figure 3. Cont. 


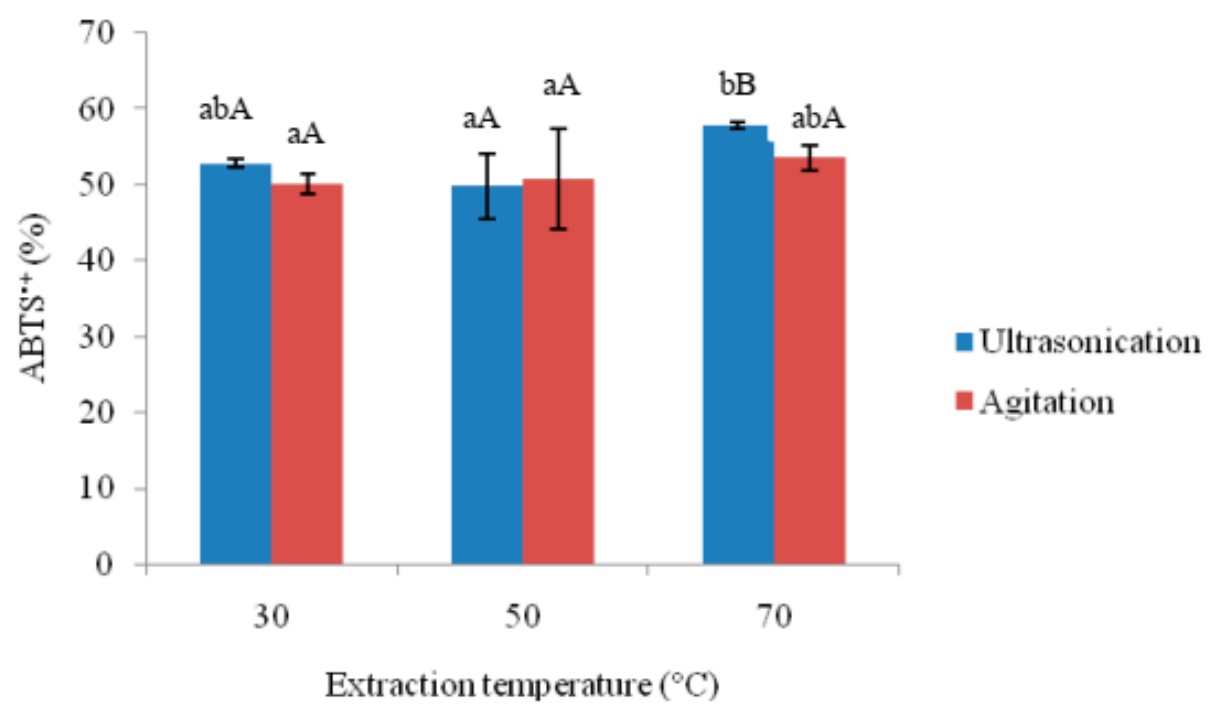

(B)

Figure 3. Effects of ultrasonication and agitation on antioxidant activities of amaranth extract. (A) $\mathrm{DPPH}^{+}$(B) $\mathrm{ABTS}^{+}$. ${ }^{\mathrm{a}-\mathrm{b}}$ Means with same subscript alphabets are not significantly different $(p \leq 0.05)$ between each extraction method. A-C Means with same subscript alphabets are not significantly different $(p \leq 0.05)$ among different temperatures in each extraction method.

\subsection{Effects of Ultra-Sonication and Agitation on Betacyanins, Betaxanthins and Betalamic Acid}

The amount of extracted betacyanins, betaxanthin and betalamic acid ranged from 4585.95 to $5325.32 \mathrm{mg} / 100 \mathrm{~g}, 1312.56$ to $1524.06 \mathrm{mg} / 100 \mathrm{~g}$ and 1408.15 to $1790.22 \mathrm{mg} / 100 \mathrm{~g}$, respectively, for ultra-sonication samples. Agitation extracted samples ranged from 4536.59 to $4758.42 \mathrm{mg} / 100 \mathrm{~g}$ for betacyanins, 1271.36 to $1317.37 \mathrm{mg} / 100 \mathrm{~g}$ for betaxanthin, and 1310.63 to $1342.2 \mathrm{mg} / 100 \mathrm{~g}$ for betalamic acid (Figure 4). Higher extraction of betacyanins, betaxanthin and betalamic acid could be due to greater of cell wall by ultra-sonication compared to agitation. However, these values were higher than those observed in other studies on edible portions of amaranthus seed $(0.07$ to $0.96 \mathrm{mg} / 100 \mathrm{~g})$, amaranthus stalks ( 0.56 to $1.54 \mathrm{mg} / 100 \mathrm{~g}$ ), amaranthus leaves (16.90 to $20.93 \mathrm{mg} / 100 \mathrm{~g})$, amaranthus flowers (0.95 to $6.02 \mathrm{mg} / 100 \mathrm{~g}$ ) and amaranthus sprouts $(2.69 \mathrm{mg} / 100 \mathrm{~g})$ [3]. These variations could be due to dissimilar methods of extraction and origin of samples [3]. In this study, higher temperature showed higher betacyanins, betaxanthin and betalamic acid compared to lower temperature for both extraction methods. Temperature significantly $(p<0.05)$ affected the betacyanins, betaxanthin and betalamic acid when ultra-sonication was employed. This might be due to increased extractability of betacyanins, betaxanthin and betalamic acid at higher temperatures. On the other hand, agitation temperature had no major impact on amaranth pigments. The three pigments followed similar trend to that of total phenolic content. In a study by Gokhale and Lele [29] on beet, betacyanin decreased but betaxanthin increased with increasing extraction temperatures. Apart from being a different sample, different extraction temperatures could have caused such differences. However, a strong correlation was found between betacyanin content and total phenol ( $r$ value of 0.97 at $p<0.05)$, betaxanthin content and total phenol $(r$ value of 0.90 at $p<0.05)$ and between betalamic acid and total phenol $(r$ value of 0.86 at $p<0.05$ ). On the other hand, correlation was also found between betacyanin content and ABTS $^{+}$ ( $r$ value of 0.94 at $p<0.05$, betaxanthin content and $\mathrm{ABTS}^{+}(r$ value of 0.87 at $p<0.05)$ and between betalamic acid and $\mathrm{ABTS}^{+} r$ value of 0.83 at $p<0.05$ ). 


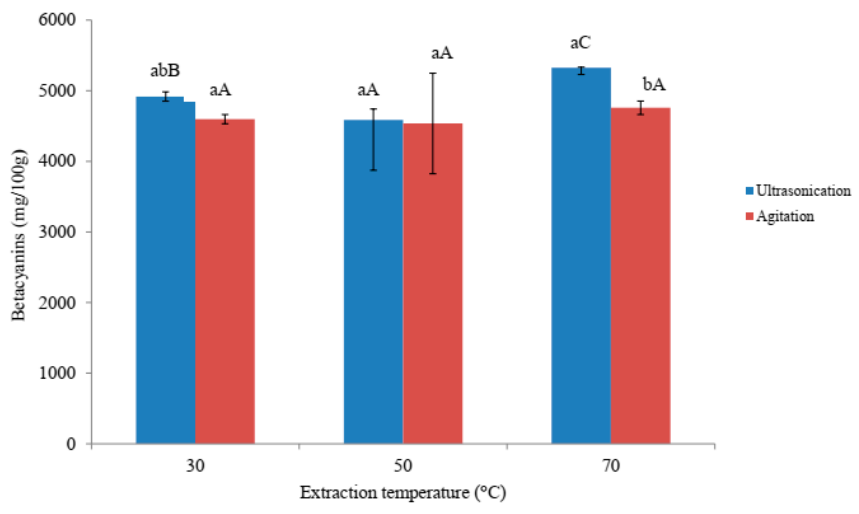

(A)

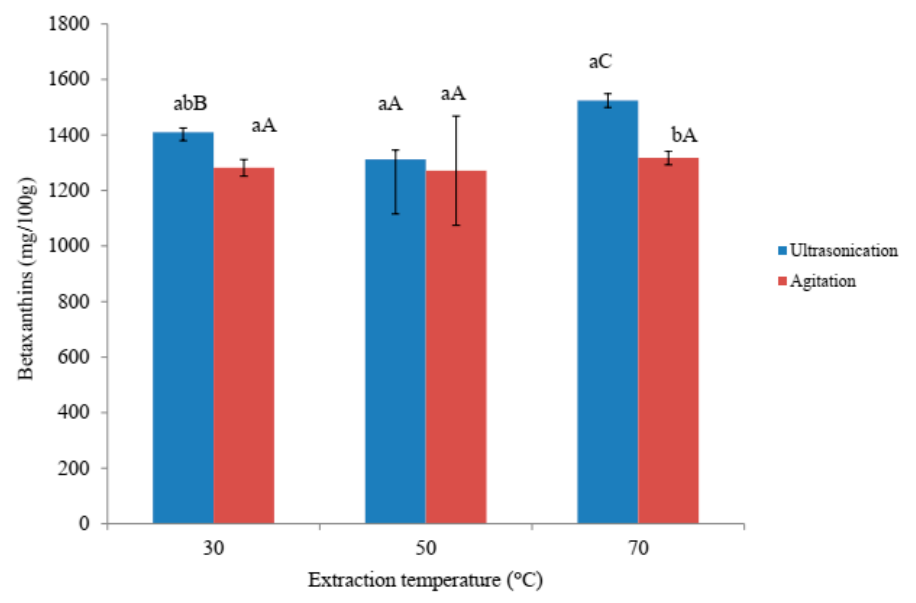

(B)

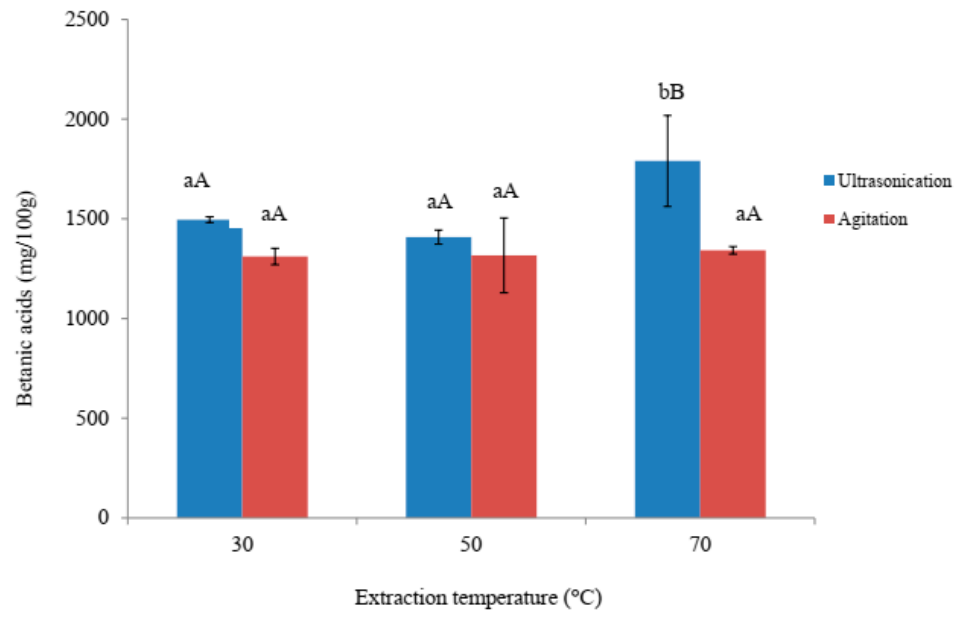

(C)

Figure 4. Effects of ultra-sonication and agitation on Betacyanins content, Betaxanthins content and Betanic acids of amaranth extract. (A) Betacyanins content (B) Betaxanthins content (C) Betalamic acid. ${ }^{\mathrm{a}-\mathrm{b}}$ Means with same subscript alphabets are not significantly different $(p \leq 0.05)$ between each extraction method. A-C Means with same subscript alphabets are not significantly different $(p \leq 0.05)$ among different temperatures in each extraction method. 


\subsection{Effects of Ultra-Soniation and Agitation on Individual Phenolic Compounds}

Individual phenolic compounds in amaranthus extracts as influenced by ultra-sonication and agitation were shown in Table 1. In this study abundant phenolic compounds found in ultra-sonicated samples were arbutin $>$ hydroxybenzoic acid $>$ ferulic acid $>p$-coumaric acid $>$ vanillic acid whereas agitated samples contained arbutin $>$ hydroxybenzoic acid $>$ vanillic acid $>$ ferulic acid $>$ $p$-coumaric acid. The changes could be attributed to different extraction methods. In a study by $\mathrm{Li}$ et al. [3] individual compounds found were gallic acid, protocatechuic acid, cholorogenic acid, getistic acid, hydroxylbenzoic acid, ferulic acid, rutin and quercetin in different parts of amaranthus species. Paśko et al. [30] found several phenolic compounds such as gallic acid, hydroxybenzoic acid, vanillic acid, $p$-coumaric acid, syringic phenolic acids in seeds and sprouts of amaranth. Different extraction methods and origin of samples might be the reason to get the variations of this result from others results. In this study, higher amounts of phenolic compounds were obtained in agitation as compared to ultra-sonication. Higher temperature $\left(70{ }^{\circ} \mathrm{C}\right)$ significantly increased arbutin and hydroxybenzoic acid as compared to lower temperature $\left(30{ }^{\circ} \mathrm{C}\right)$ in ultra-sonication methods. On the other hand, in agitation methods, only arbutin increased significantly but not hydroxybenzoic acid at higher temperature $\left(70{ }^{\circ} \mathrm{C}\right)$ than at lower temperature $\left(30^{\circ} \mathrm{C}\right)$. However, vanillic acid, $p$-coumaric acid and ferulic acid remained unaffected irrespective of temperature for both the methods. Agitation retained higher amount of total phenolic compounds than those of ultra-sonication techniques at higher temperature. Increases in arbutin and hydroxybenzoic acid might be extracted from bound polyphenols, as studies have shown that bound polyphenols might be released the disruption of the cell wall [29]. Sonication and agitation have ability to disrupt the cell wall $[24,25]$. The reduction in vanillic acid and ferulic acid could be due to enzymatic degradation or co-pigmentation reaction [30]. In a study by Mphahlele et al. [31] on pomegranate peel, a higher amount of rutin, $p$-coumaric, catechin, and epicatechin but lower amounts of hesperid were observed at 60 compared to $30^{\circ} \mathrm{C}$. In this study, the amounts of vanillic acid (35 to $158.4 \mu \mathrm{g} / \mathrm{g}$ ), ferulic acid (73.8 to $93.76 \mu \mathrm{g} / \mathrm{g}), p$-coumaric acid ( 28.80 to $69.91 \mu \mathrm{g} / \mathrm{g}$ ) and hydroxybenzoic acid (1519.40 to $2183.88 \mu \mathrm{g} / \mathrm{g}$ ) measure were consistent with that of Venskutonis and Kraujalis [32], who studied various amaranth species. However, the hydroxybenzoic acid level (1519.40 to $2183.88 \mu \mathrm{g} / \mathrm{g})$ was much higher than amaranthus seeds and sprouts ( 8 to $20 \mu \mathrm{g} / \mathrm{g}$ ) [23]. There is no information available about arbutin in amaranth. Nonetheless, cultivated species and different extraction methods might be reason to get the variation results from other researchers. 
Table 1. Effects of ultra-sonication and agitation on phenolic compounds $(\mu \mathrm{g} / \mathrm{g})$ of amaranth extract.

\begin{tabular}{|c|c|c|c|c|c|c|}
\hline \multirow{2}{*}{ Parameters } & \multicolumn{6}{|c|}{ Extraction Method } \\
\hline & US 30 & US 50 & US 70 & AG 30 & AG 50 & AG 70 \\
\hline Arbutin & A $26485.60 \pm 2544.45^{\mathrm{a}}$ & A $26691.20 \pm 1821.51^{\mathrm{a}}$ & B $48458.40 \pm 3920.77^{c}$ & A $19419.4 \pm 1549.13^{a}$ & B $35148.4 \pm 2588.01{ }^{b}$ & $\mathrm{C}^{2} 53958.8 \pm 5624.61^{\mathrm{c}}$ \\
\hline Hydroxybenzoic acid & $\mathrm{AB} 1817.20 \pm 101.26^{\mathrm{ab}}$ & A $1519.40 \pm 135.48^{\mathrm{a}}$ & B $1898.80 \pm 110.311^{\mathrm{ab}}$ & ${ }^{\mathrm{A}} 1654.2 \pm 189.22^{\mathrm{a}}$ & A $2183.88 \pm 76.54^{\mathrm{b}}$ & ${ }^{\mathrm{A}} 2153.2 \pm 236.46^{\mathrm{b}}$ \\
\hline Vanillic acid & A $35.08 \pm 4.92^{\mathrm{a}}$ & A $31.72 \pm 2.55^{\mathrm{a}}$ & A $35.84 \pm 1.33^{\mathrm{a}}$ & $\mathrm{A} 158.4 \pm 1.7^{\mathrm{b}}$ & A $147.8 \pm 91.36^{\mathrm{b}}$ & A $146.6 \pm 74.39^{\mathrm{b}}$ \\
\hline$p$-coumaric acid & A $57.84 \pm 1.7$ bc & A $57.48 \pm 15.67 \mathrm{bc}$ & A $28.80 \pm 0.09^{\mathrm{a}}$ & A $69.96 \pm 7.86^{\mathrm{c}}$ & A $61.4 \pm 14.65^{\mathrm{bc}}$ & A $39.36 \pm 2.26^{\mathrm{ab}}$ \\
\hline Ferulic acid & A $79.84 \pm 5.88^{a b}$ & A $77.68 \pm 10.3^{\mathrm{ab}}$ & A $76.00 \pm 2.38^{a}$ & ${ }^{\mathrm{AB}} 85.16 \pm 3.11^{\mathrm{ab}}$ & A $73.8 \pm 5.6^{\mathrm{a}}$ & B $93.76 \pm 7.01^{b}$ \\
\hline Total phenolic compounds & A $28475.56 \pm 2644.97^{\mathrm{a}}$ & ${ }^{\mathrm{A}} 28377.45 \pm 1980.36^{\mathrm{a}}$ & ${ }^{C} 50371.20 \pm 3924.38^{c}$ & A $23657.24 \pm 1481.36^{\mathrm{a}}$ & B $36819.16 \pm 1650.274^{b}$ & $\mathrm{C}^{\mathrm{C}} 53311.12 \pm 1569.55^{\mathrm{c}}$ \\
\hline
\end{tabular}




\subsection{Structural Changes}

FTIR analysis was performed to ascertain any structural changes induced by ultra-sonication and agitation treatments on amaranth extract. FTIR spectra of the amaranth extracts were shown in Figure 5a-f. Carbonyl $(\mathrm{C}=\mathrm{O})$ and amines group $(\mathrm{N}-\mathrm{H})$ are considered to represent the betacyanin group of betalains pigments [33]. The intensity of bands at 1636.69 to $1637.49 \mathrm{~cm}^{-1} ; 2088.96$ to $2125.76 \mathrm{~cm}^{-1}$; 3309.94 to $3311.54 \mathrm{~cm}^{-1}$ was observed for agitation extracted samples whereas the peak at 1637.33 to $1637.71 \mathrm{~cm}^{-1} ; 2097.60$ to $2099.14 \mathrm{~cm}^{-1} ; 3292.59$ to $3309.80 \mathrm{~cm}^{-1}$ was identified for the ultra-sonication extracted samples. Skenderidis et al. [34] found the peak at 1720 and $3315 \mathrm{~cm}^{-1}$ to be responsible for the carboxyl group and hydroxyl group, respectively, in the ultrasound-assisted extraction of lyophilized powdered pomegranate peel. Biswas et al. [2] also mentioned that the 1653 to $918 \mathrm{~cm}^{-1}$ band represented the functional group of betacyanin in amaranth tricolor pigments. Cai et al. [35] also showed the presence of functional group of betacyanin at $1720-714 \mathrm{~cm}^{-1}$ in Amaranthus pigments. These variations may be due to the $\mathrm{C}=\mathrm{O}$ and $\mathrm{N}-\mathrm{H}$ group. On the other hand, the absorption bands at 3264 to $3311.54 \mathrm{~cm}^{-1}$ were found in amaranth extract. These regions represent the $-\mathrm{NH} 2,-\mathrm{OH}$, $-\mathrm{H}_{2} \mathrm{O}$ and C-S functional group. Functional group could vary due to protein, amino acid and water in the pigments [2]. In this study, FTIR results showed that ultra-sonication and agitation resulted in similar effect on structure of amaranth extracts.

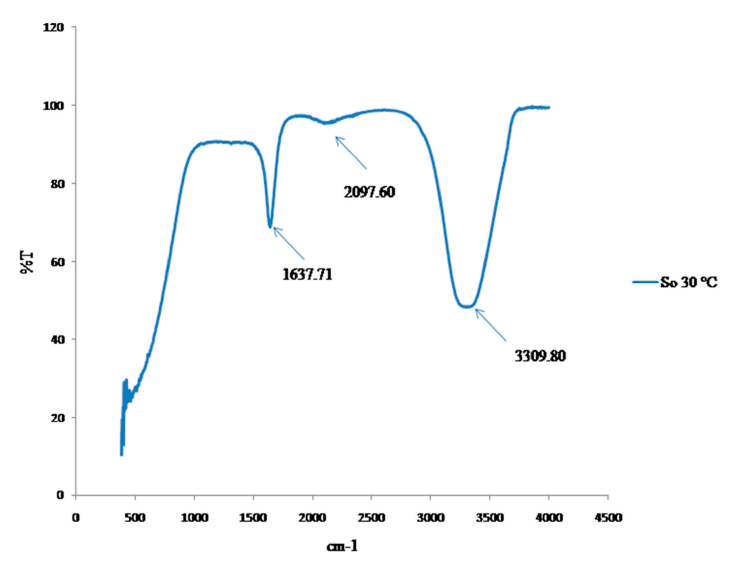

(a)

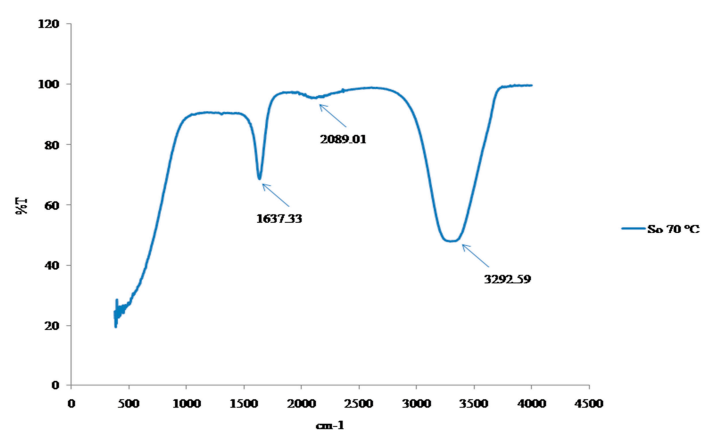

(c)

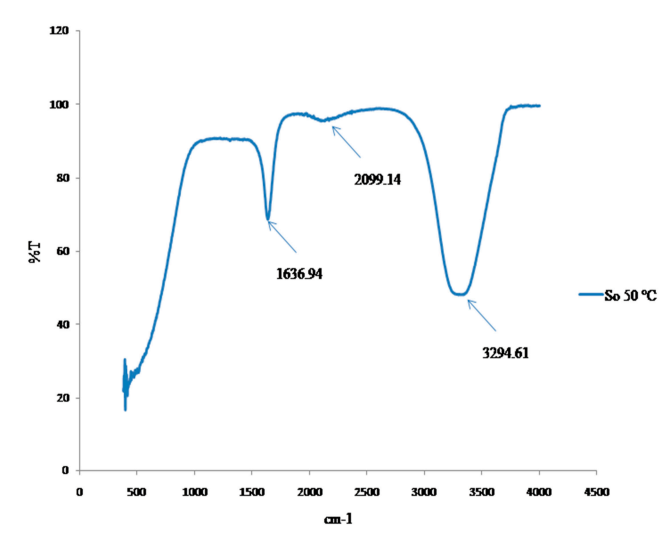

(b)

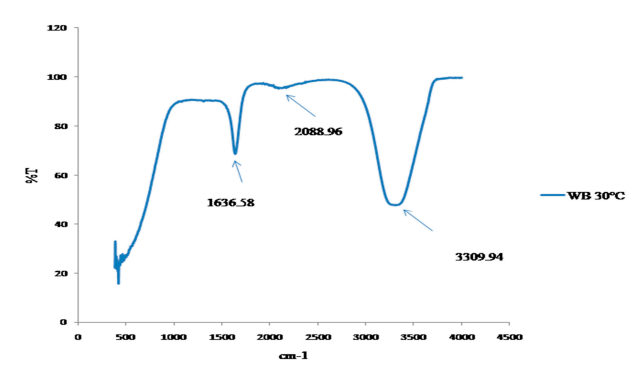

(d)

Figure 5. Cont. 


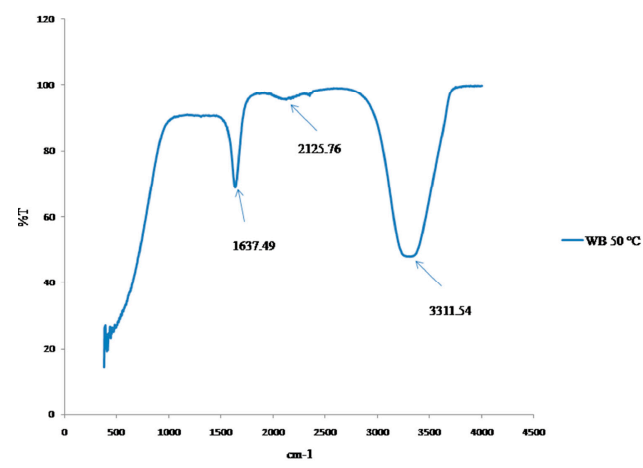

(e)

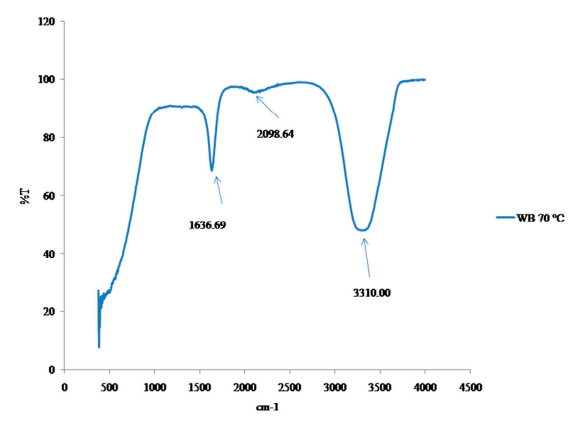

(f)

Figure 5. Fourier-transform infrared (FTIR) spectroscopy analysis of amaranth extract. (a) Ultra-sonication at $30{ }^{\circ} \mathrm{C}$, (b) ultra-sonication at $50{ }^{\circ} \mathrm{C}$, (c) ultra-sonication at $70{ }^{\circ} \mathrm{C}$, (d) agitation in water bath (WB) at $30^{\circ} \mathrm{C}$, (e) agitation water bath (WB) at $50^{\circ} \mathrm{C}$, and (f) agitation water bath (WB) at $70{ }^{\circ} \mathrm{C}$.

\subsection{Principal Component Analysis (PCA)}

Relationship between data and samples were identified by PCA in this study. The results indicated that components PC1 $(58.65 \%)$ and components PC2 $(23.55 \%$, ) were accountable of the total variance and presented Eigen values 8.79 for PC1 and 3.53 for PC2, which were greater than 1.0. The results showed that all phenol, flavonoid, betacyanins, betaxanthins and betalamic acid were associated with ultra-sonication (US) $70{ }^{\circ} \mathrm{C}$ whereas $\mathrm{DPPH}^{+}, \mathrm{ABTS}^{+}$, arbutin and hydroxybenzoic acid were associated with water bath (WB) $70{ }^{\circ} \mathrm{C}$. These phenomena might be related to the amount of compounds. Higher negative scores were correlated with $\mathrm{PC} 1$ along with phenol, flavonoid, $\mathrm{DPPH}^{+}$, ABTS $^{+}$betacyanins, betaxanthins betanic acids, arbutin, hydroxybenzoic, ferulic acid (Table 2, Figure 6). On the other hand, higher positive scores were associated with PC2 along with arbutin, hydorxybenzoic acid, vanillic acid and ferulic acid (Table 2 and Figure 5). However, negative scores were observed with $L^{*}$ and $b^{*}$ in PC2 (Table 2). Therefore, results showed the correlations between data and samples using principal components analysis that could be useful to choosing the extraction method.

Table 2. Factor loading, eigenvalue, cumulative variance (\%) and score for the first two principal (PC1. and PC2) components of amaranth extract based on extraction methods.

\begin{tabular}{ccc}
\hline Loading & PC 1 & PC2 \\
\hline $\mathrm{L}^{*}$ & -0.871 & -0.315 \\
\hline $\mathrm{a}^{*}$ & -0.884 & 0.195 \\
\hline $\mathrm{b}^{*}$ & 0.516 & -0.737 \\
\hline Phenol & -0.945 & -0.056 \\
\hline Flavonoid & -0.747 & -0.080 \\
\hline DPPH $^{+}$ & -0.756 & 0.562 \\
\hline ABTS $^{+}$ & -0.949 & 0.044 \\
\hline Betacyanins $^{*}$ & -0.903 & -0.289 \\
\hline Betaxanthins & -0.847 & -0.453 \\
\hline Betanic acids & -0.851 & -0.498 \\
\hline Arbutin & -0.795 & 0.521 \\
\hline Hydroxybenzoic & -0.317 & 0.762 \\
\hline Vanillicacid & 0.379 & 0.863 \\
\hline
\end{tabular}


Table 2. Cont.

\begin{tabular}{ccc}
\hline Loading & PC 1 & PC2 \\
\hline Paracoumaric & 0.966 & -0.109 \\
\hline Ferulic acid & -0.005 & 0.616 \\
\hline Scores & & \\
\hline US 30 & 0.831 & -1.771 \\
\hline US 50 & 1.767 & -2.152 \\
\hline US 70 & -5.891 & -1.068 \\
\hline WB 30 & 3.042 & 0.390 \\
\hline WB50 & 1.704 & 1.420 \\
\hline WB70 & -1.454 & 3.180 \\
\hline
\end{tabular}

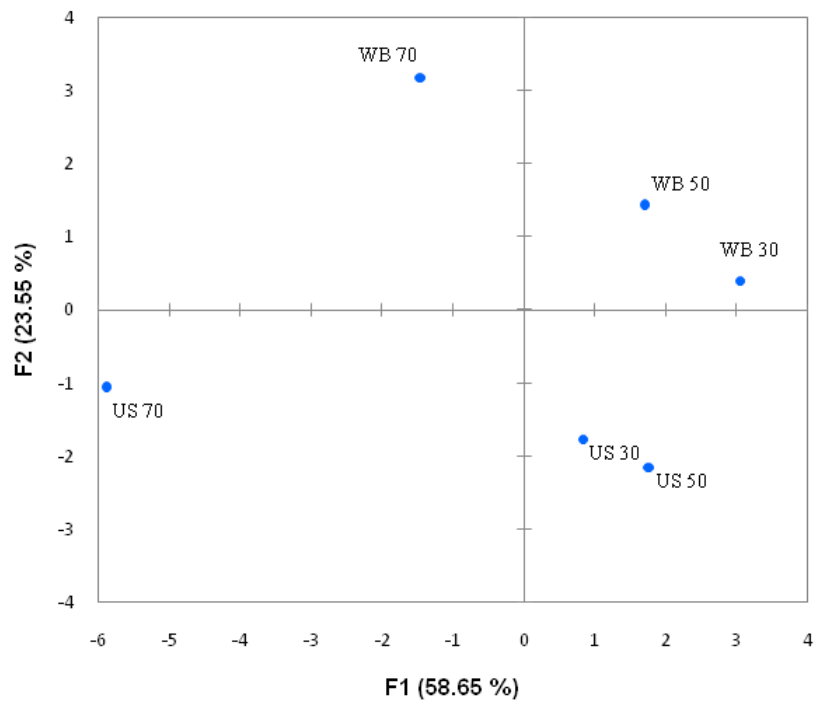

(A)

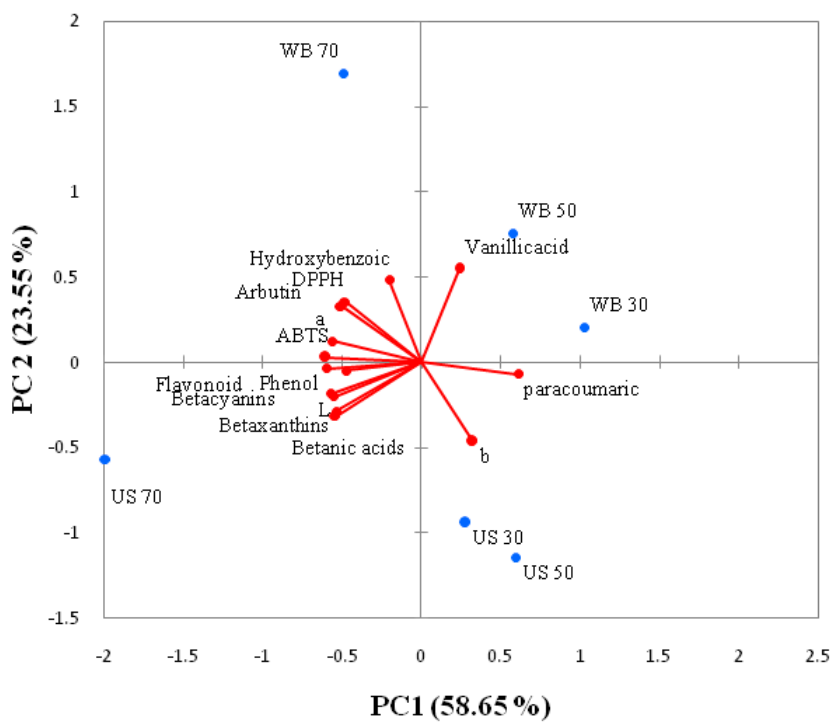

(B)

Figure 6. Principal component analysis of amaranth extract. (A) Parameter loading; (B) sample scores. 


\section{Conclusions}

The effects of ultra-sonication and agitation extractions at 30,50 and $70{ }^{\circ} \mathrm{C}$ on bioactive compounds, antioxidant activities and structure changes of amaranth extract were investigated. No significant differences were observed in total phenol, total flavonoid, $\mathrm{DPPH}^{+}, \mathrm{ABTS}^{+}$scavenging activity, betacyanins, betaxanthin and betalamic acid of amaranth extracts prepared using ultra-sonication and agitation. A higher temperature led to increased total phenolic compounds in the amaranth extracts. Both extraction methods did not affect the structures, which were analyzed using FTIR. A connection was established between the extraction methods and the nutritional components by principal component analysis. Therefore, agitation extraction at $70{ }^{\circ} \mathrm{C}$ could be considered as an efficient method, which could also serve as an alternative for ultra-sonication in the derivation of bioactive compounds from amaranth extracts.

Author Contributions: M.A., K.R. and G.-H.J. worked on conceptualization, methodology, software, validation, formal analysis, investigation, resources, data curation, original draft preparation, review and editing. J.B.E. worked on visualization and supervision. All authors have read and agreed to the published version of the manuscript.

Funding: This research received no external funding.

Conflicts of Interest: The authors declare no conflict of interest.

\section{References}

1. Khandaker, L.; Ali, M.B.; Oba, S. Total polyphenol and antioxidant activity of red amaranth (Amaranthus tricolor L.) as affected by different sunlight level. J. Jpn. Soc. Hortic. Sci. 2008, 77, 395-401. [CrossRef]

2. Biswas, M.; Dey, S.; Sen, R. Betalains from Amaranthus tricolor L. J. Pharmacogn. Phytochem. 2013, 1, 87-95.

3. Li, H.; Deng, Z.; Liu, R.; Zhu, H.; Draves, J.; Marcone, M.; Sun, Y.; Tsao, R. Characterization of phenolics, betacyanins and antioxidant activities of the seed, leaf, sprout, flower and stalk extracts of three Amaranthus species. J. Food Compos. Anal. 2015, 37, 75-81. [CrossRef]

4. Al-Mamun, M.A.; Husna, J.; Khatun, M.; Hasan, R.; Kamruzzaman, M.; Hoque, K.M.F.; Reza, M.A.; Ferdousi, Z. Assessment of antioxidant, anticancer and antimicrobial activity of two vegetable species of Amaranthus in Bangladesh. BMC Complement. Altern. Med. 2016, 16, 1-11.

5. Khanam, U.K.S.; Oba, S. Bioactive substances in leaves of two amaranth species, Amaranthus tricolor and A. hypochondriacus. Can. J. Plant Sci. 2013, 93, 47-58.

6. Sandoval-Sicairos, E.S.; Domínguez-Rodríguez, M.; Montoya-Rodríguez, A.; Milán-Noris, A.K.; Reyes-Moreno, C.; Milán-Carrillo, J. Phytochemical Compounds and Antioxidant Activity Modified by Germination and Hydrolysis in Mexican Amaranth. Plant Foods Hum. Nutr. 2020, 75, 192-199. [CrossRef]

7. Sindhuja, A.; Sudha, M.L.; Rahim, A. Effect of incorporation of amaranth flour on the quality of cookies. Eur. Food Res. Technol. 2005, 221, 597-601.

8. Priatni, S.; Pradita, A. Stability study of betacyanin extract from red dragon fruit (Hylocereuspolyrhizus) peels. Procedia Chem. 2015, 16, 438-444.

9. Kumar, S.S.; Manoj, P.; Shetty, N.P.; Prakash, M.; Girindhar, P. Characterization of major betalain pigments-gomphrenin, betanin and isobetanin from basellaruba L. fruit and evaluation of efficacy as a natural colourant in product (ice cream) development. J Food Sci. Technol. 2015, 52, 4994-5002. [CrossRef]

10. De Azeredo, H.M.C.; Pereira, A.C.; de Souza, A.C.R.; Gouveia, S.T.; Mendes, K.C.B. Study on efficiency of betacyanin extraction from red beetroots. Int. J. Food Sci. Technol. 2009, 44, 2464-2469.

11. Medina Meza, I.G.; Boioli, P.; Barbosa Cánovas, G.V. Assessment of the Effects of Ultrasonics and Pulsed Electric Fields on Nutritional and Rheological Properties of Raspberry and Blueberry Purees. Food Bioprocess Technol. 2016, 9, 520-531. [CrossRef]

12. Sue-Siang, T.; Birch, E.J. Effect of ultrasonic treatment on the polyphenol content and antioxidant capacity of extract from defatted hemp, flax and canola seed cakes. Ultrason. Sonochem. 2014, 21, 346-353.

13. Altemimi, A.; Watson, D.G.; Choudhary, R.; Dasari, M.R.; Lightfoot, D.A. Ultrasound Assisted Extraction of Phenolic Compounds from Peaches and Pumpkins. PLoS ONE 2016, 11, e0148758. [CrossRef] [PubMed] 
14. Medina-Torres, N.; Ayora-Talavera, T.; Espinosa-Andrews, H.; Sánchez-Contreras, A.; Pacheco, N. Ultrasound assisted extraction for the recovery of phenolic compounds from vegetable sources. Agronomy 2017, 7, 47. [CrossRef]

15. Skenderidis, P.; Petrotos, K.; Giavasis, I.; Hadjichristodoulou, C.; Tsakalof, A. Optimization of ultrasound assisted extraction of of goji berry (Lycium barbarum) fruits and evaluation of extracts' bioactivity. J. Food Process. Eng. 2017, 40, e12522. [CrossRef]

16. Sifaoui, I.; Chammem, N.; Abderrabba, M.; Mejri, M. Optimization of Phenolic compounds Extractionfrom Olive Leaves using Experimental Design Methodology. J. Mater. Environ. Sci. 2016, 7, 1119-1127.

17. Okafor, S.N.; Obonga, W.; Ezeokonkwo, M.A.; Nurudeen, J.; Orovwigho, U.; Ahiabuike, J. Assessment of the Health implications of Synthetic and Natural Food Colourants A Critical Review. UK J. Pharm. Biosci. 2016, 4, 1-11. [CrossRef]

18. Das, M.; Saeid, A.; Hossain, M.F.; Jiang, G.H.; Eun, J.B.; Ahmed, M. Influence of extraction parameters and stability of betacyaninsextracted from red amaranth during storage. J. Food Sci. Technol. 2019, 56, 643-653.

19. Lee, B.R.; Muneera, S.; Jung, W.J.; Aviced, J.C.; Ourryd, A.; Kima, T.H. Mycorrhizal colonization alleviates drought-induced oxidative damage and lignification in the leaves of drought-stressed perennial ryegrass (Loliumperenne). Physiol. Plant. 2012, 145, 440-449. [CrossRef]

20. Hajimahmoodi, M.; Hanifeh, M.; Oveisi, M.R.; Sadeghi, N.; Jannat, B. Determination of total antioxidant capacity of green teas by the ferric reducing/antioxidant power assay. Iran. J. Environ. Health Sci. Eng. 2008, 3, 167-172.

21. Yim, S.; Nam, S. Physiochemical, nutritional and functional characterization of 10 different pear cultivars (Pyrus spp.). J. Appl. Bot. Food Qual. 2016, 89, 73-81.

22. Dong, W.; Hu, R.; Chu, Z.; Zhao, J.; Tan, L. Effect of different drying techniques on bioactive components, fatty acid composition, and volatile profile of robusta coffee beans. Food Chem. 2017, 234, 121-130. [CrossRef] [PubMed]

23. Călinoiu, L.F.; Vodnar, D.C. Thermal Processing for the Release of PhenolicCompounds from Wheat and Oat Bran. Biomolecules 2020, 10, 2-14.

24. Ashokkumar, M.; Sunartio, D.; Kentish, S.; Mawson, R.; Simons, L.; Vilkhu, K.; Versteeg, C. Modification of food ingredients by ultrasound to improve functionality: A preliminary study on a model system. Innov. Food Sci. Emerg. Technol. 2008, 9, 155-160. [CrossRef]

25. Abid, M.; Jabbar, S.; Wu, T.; Hashim, M.M.; Hu, B.; Lei, S.; Zeng, X. Effect of ultrasound on different quality parameters of apple juice. Ultrason. Sonochem. 2013, 20, 1182-1187. [CrossRef] [PubMed]

26. Bhat, R.; Goh, K.M. Sonication treatment convalesce the overall quality of hand-pressed strawberry juice. Food Chem. 2017, 215, 470-476. [CrossRef]

27. Muhamad, N.; Muhmed, S.A.; Yusoff, M.M.; Gimbun, J. Influence of Solvent Polarity and Conditions on Extraction of Antioxidant, Flavonoids and Phenolic Content from Averrhoabilimbi. J. Food Sci. Eng. 2014, 4, 255-260.

28. Okoh, S.O.; Asekun, O.T.; Familoni, O.B.; Afolayan, A.J. Antioxidant and Free Radical Scavenging Capacity of Seed and Shell Essential Oils Extracted from Abrus precatorius (L.). Antioxidants 2014, 3, 278-287. [CrossRef]

29. Gokhale, S.V.; Lele, S.S. Betalain content and antioxidant activity of beta vulgaris: Effect of hot air convective drying and storage. J. Food Process. Preserv. 2014, 38, 585-590. [CrossRef]

30. Paśko, P.; Sajewicz, M.; Gorinstein, S.; Achwieja, Z.Z. Analysis of Selected Phenolic Acids and Flavonoids in Amaranthuscruentus and Chenopodium quinoa Seeds and Sprouts by HPLC. Acta Chromatogr. 2008, 20, 661-672.

31. Mphahlele, R.R.; Fawole, O.A.; Makunga, N.P.; Opara, U.L. Effect of drying on the bioactive compounds, antioxidant, antibacterial and antityrosinase activities of pomegranate peel. BMC Complement. Altern. Med. 2016, 16, 143. [CrossRef] [PubMed]

32. Venskutonis, P.R.; Kraujalis, P. Nutritional components of amaranth seeds and vegetables: A Review on composition, properties, and uses. Compr. Rev. Food Sci. Food Saf. 2013, 12, 381-412. [CrossRef]

33. Narayan, M.R. Review: Dye sensitized solar cells based on natural photosensitizers. Renew. Sustain. Energy Rev. 2012, 16, 208-215. [CrossRef] 
34. Skenderidis, P.; Mitsagga, C.; Giavasis, I.; Petrotos, K.; Lampakis, D.; Leontopoulos, S.; Hadjichristodoulou, C.; Tsakalof, A. The in vitro antimicrobial activity assessment of ultrasound assisted Lycium barbarum fruit extracts and pomegranate fruit peels. J. Food Meas. Charact. 2019, 13, 2017-2031. [CrossRef]

35. Cai, Y.; Wu, H.; Huang, R.; Corke, H. Characterization and Quantification of Betacyanin Pigments from Diverse Amaranthus Species. J. Agric. Food Chem. 1998, 46, 2063-2070. [CrossRef]

(C) 2020 by the authors. Licensee MDPI, Basel, Switzerland. This article is an open access article distributed under the terms and conditions of the Creative Commons Attribution (CC BY) license (http://creativecommons.org/licenses/by/4.0/). 